\title{
Como Medir o Valor da Relação Médico-Paciente? Experiência com um Instrumento de Medida da Percepção de Pacientes do Comportamento Comunicativo do Médico
}

\author{
Valle, Estevao Alves; Assunção, Fernando Cézar Menezes; Camargo Neto, Geraldo \\ Barcellos \\ +60 Saúde - ESTEVAO@MAIS60SAUDE.COM.BR
}

Introdução: Problemas relacionados à comunicação médico-paciente são comuns, mesmo em países onde a qualidade dos serviços médicos é supostamente superior à do Brasil. a comportamento comunicativo durante o atendimento médico tem sido relacionado com diversos desfechos em saúde, positivos e negativos. Aprimorar o processo comunicativo, através da percepção dos pacientes, proporciona amplas possibilidades de mudanças e inovações, no ensino e na prática assistencial. Objetivos: Apresentar resultados da aplicação do Questionário do Comportamento Comunicativo do Médico (QCCM), escala validada no Brasil, componente do Projeto de Humanização do Atendimento ao Idoso Portador de Doença Renal, em Betim, Minas Gerais. Método: Estudo transversal em amostra de 55 indivíduos, com 60 ou mais anos de idade. o questionário foi aplicado em janeiro de 2014, imediatamente após as consultas, por profissional não vinculado ao atendimento. As percepções dos pacientes sobre o comportamento comunicativo dos médicos foi avaliada segundo as médias das respostas para cada dimensão do questionário. Resultados: Os indivíduos parecem conceber, primeiramente, que os médicos são compreensíveis e amigáveis. em segundo lugar, demonstram apoio não-verbal. Quanto à escala "Encorajamento e elogio", ela apresenta como média a resposta "frequentemente" ( $M=3,88)$ e, na escala "Controle", a resposta "às vezes" (M $=3,46)$. Conclusões: Os entrevistados no estudo parecem dizer: "na relação com esses médicos, percebemos que são compreensíveis e amigáveis e demonstram apoio nãoverbal por meio de seus comportamentos. Eles também nos encorajam com certa frequência a nos expressarmos durante o processo de tratamento, mas somente às vezes abrem mão do controle exercido na construção das opções terapêuticas". Através do QCCM, será possível utilizá-la como um parâmetro objetivo da eficácia comunicativa do médico em relação aos desfechos de saúde. Permite também a auto-avaliação do médico e entender pontos de melhoria na humanização dos atendimentos.

Valle, Estevao Alves; Assunção, Fernando Cézar Menezes; Camargo Neto, Geraldo Barcellos. Como Medir o Valor da Relação Médico-Paciente? Experiência com um Instrumento de Medida da Percepção de Pacientes do Comportamento Comunicativo do Médico. In: Anais do Congresso Internacional de Humanidades \& Humanização em Saúde [= Blucher Medical Proceedings, num.2, vol.1]. São Paulo: Editora Blucher, 2014. ISSN 2357-7282

DOI 10.5151/medpro-cihhs-10800 